SiIEEl' G (Laml), 6 months).

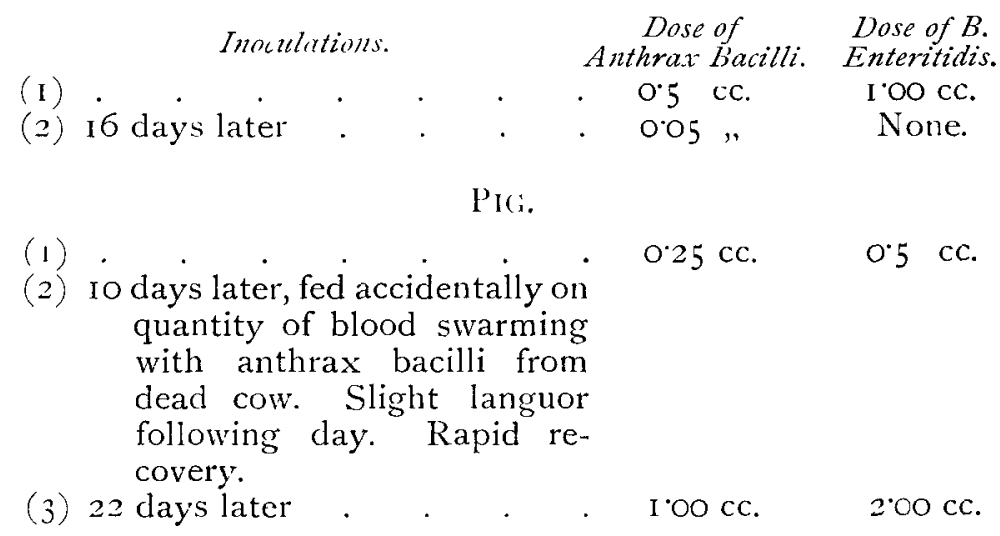

\title{
AURICULAR ACARIASIS.
}

By FRANK GARNETT, M.R.C.V.S., Windermere.

THE classification of the order acarina, though far from being finally settled in regard to the position which some of its families may hold, is sufficiently clear as regards the position of the sarcoptida. The magnitude of the work of classifying this huge order has been attempted by many naturalists during the past century. Linnæus in I 735 treated it as one genus, but De Geer may be said to have been the first, in 1778 , to attempt a classification, following whom we have Latreille and Herman in ISo6, C. Von Hayden in I 828, Duges (1839), Kock (1842), Nicolet (1855), Fruistenberg (186I), Donadieu (I 875), Magnin (1876), Kramar ( I 877 ), Michael (1884), and in I89 I Canestrini of Padua and Trouessart of Paris.

Each succeeding acarologist since De Geer's first classification has differed from his predecessors, some dividing the order according to a single organ, as palpi; form, as vermiform and non-vermiform ; habitat, as terrestrial and aquatic; till P. Kramar of Schlensingen divided the order by the trachea into tracheata and atracheata, which main divisions have been generally accepted till the classifications of I 89 I appeared.

Canestrini (1891) treats the acari as a class, and divides it into six orders, the first of which is astigmata, which is divided into two suborders ( 1 ) vermiforma, (2) sarcoptina; the former is divided into two families, of which one is the demodicidæ, the latter into seven families, the second of which, psoroptidæ, contains three genera, sarcoptes, psoroptes, and symbiotes. In Dr Trouessart's I 89 I classification the mites are divided into two orders, acarina and vermiformia, the latter containing the family demodicida. The acarina he divides into three sub-orders, prostigmata, metastigmata, and astigmata, the last containing a single family, sarcoptidx, which he divides into six subfamilies, included in which is the sarcoptinæ.

It is to the astigmata or atracheata (Kramar), without trachea and 
therefore without stigmata, that the family sarcoptidæ belong, the respiration being entirely cutaneous. The acari belonging to this family may be distinguished by having in the adult four pairs of legs of five articles each, attached to a soft body by chitinous epimera; the mandibles are chelate, and there are no eyes.

The sarcoptida is a very large family, and is divided into five to seven sub-families, of which one, sarcoptidæ psorica or sarcoptinæ, contains all the acari parasitic to animals and causing the disease known as scabies, with the exception of demodectic scabies, the parasite of which belongs to the family demodicida.

The sub-family sarcoptinæ is divided into three distinct genera, sarcoptes, psoroptes, and symbiotes, each supplying one or more species producing a distinct form of scabies.

The sarcoptes are divided into two species, sarcoptes scabiei and sarcoptes minor, the former attacking horses, dogs, cattle, and pigs, while the latter are peculiar to cats and rabbits, The form of mange caused by either of these species is the most troublesome to eradicate on account of the burrowing proclivities of the ovigerous female. The genus psoroptes contains a single species, psoroptes communis, and it is the variety ovis of this species which is the cause of the disease known in this country as sheep scab. The species also attacks horses, cattle, and rabbits.

The genus symbiotes contains four species, two of which are known respectively as symbiotes communis and symbiotes auricularum. The former produces by far the commonest form of parasitic affection among horses, and the latter species is a very frequent cause of auricular disease in dogs and cats.

The following classification of parasitic acari producing scabies in the domestic animals would, I think, be accepted as correct by all naturalists at the present time.

\begin{tabular}{|c|c|c|c|c|c|}
\hline order. & Sub-order. & Fumily. & Sub-family. & Genert. & Sprocies. \\
\hline Acarina & $\begin{array}{l}\text { Astigmata } \\
\text { or } \\
\text { Astracheata }\end{array}$ & Sarcoptidæ & $\begin{array}{l}\text { Sarcoptidie } \\
\text { psorica or } \\
\text { Sarcoptineæ }\end{array}$ & $\left\{\begin{array}{l}\text { Sarcoptes } \\
\text { Psoroptes } \\
\text { Symbiotes }\end{array}\right.$ & $\begin{array}{l}\left\{\begin{array}{l}\text { Sareoptes scabiei. } \\
\text { Sarcoptes minor. }\end{array}\right. \\
\text { Psoroptes communis. } \\
\left\{\begin{array}{l}\text { Symbiotes communis. } \\
\text { Symbiotes auricularum. }\end{array}\right.\end{array}$ \\
\hline
\end{tabular}

Symbiotes auricularum as a cause of otitis in dogs and cats has received but little attention at the hands of English veterinarians, and, with the exception of Mr A. J. Sewell in I89I, in the Veterinary Journal of that year, I can find no recorded cases, yet it is undoubtedly one of the commonest causes of that common disease in both these animals which we are called upon to treat. Mr Sewell, in the communication referred to, calls the parasite psoroptes auricularis canis, but his illustrations, incorrect though they are in certain details, are sufficiently well drawn for anyone who is acquainted with the two species to say that it is not a psoropt but a symbiot, and, further, that it is the parasite now known as symbiotes auricularum, though in his description he mistakes the ova for larval forms, the adult 
female for a male, and the pubescent female for a female, while the male is not figured at all.

It is usual to speak of symbiotes auricularum var. canis and var. cati, respectively, when the parasite is found in the ear of the dog or cat as the case may be. I am of opinion that they should not be treated as separate varieties, as I do not consider that habitat alone is of itself sufficient to make a distinct variety, the parasite being identical

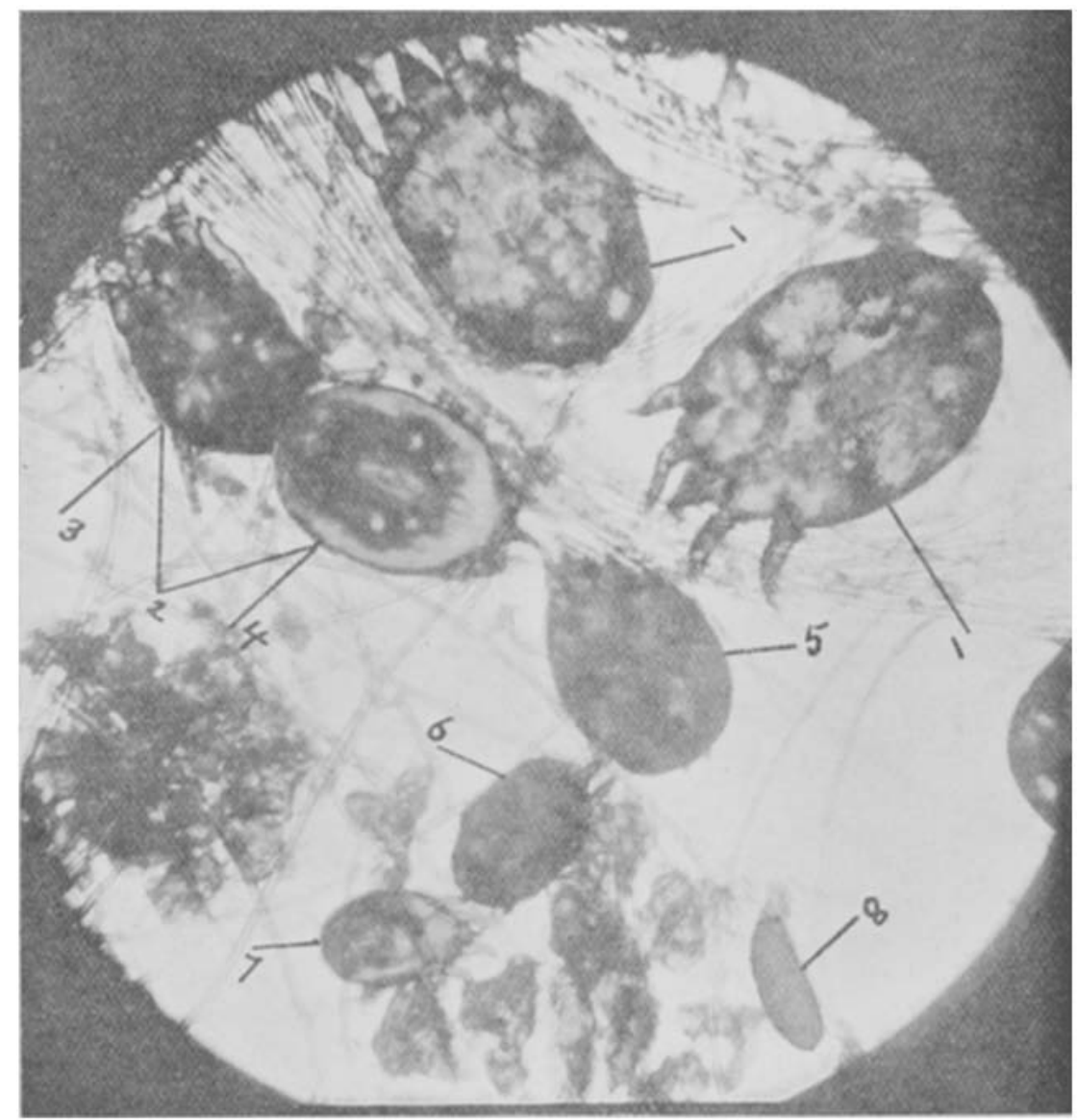

FIIT. 1.

Dry slip preparation of psoroptes communis var. ovis $(\lambda .50)$. 1. Ovigerous females with ova. 2. Pair conpled. 3. Male. 4 and 5. Pubescent females. 6. Nympha. 7. Hexapod larva. 8 Ovum.

in every other respect. I have not been able to distinguish any external anatomical difference in the acari obtained from these two animals, though Neumann gives the size of the auricular symbiot of the dog as being larger than that of the cat.

The following case inclines me to the opinion that the parasite is intercommunicable from dog to cat. I treated a collie dog, which lived luxuriously in the house, for canker in the ear due to symbiotes auricularum. I ceased treating it before cure was complete, as the 
owner thought it had so far recovered that it would go on without further attention. In the house was a cat of a wild disposition which could not be induced to go near the dog. Soon after I had given up treating the dog the owner had two kittens given from different homes. They became very friendly with the dog, all three constantly lying together before the fire or in the sun. About eight months after I first treated the dog it was brought again suffering from the disease in a more aggravated form, and I was also requested to go

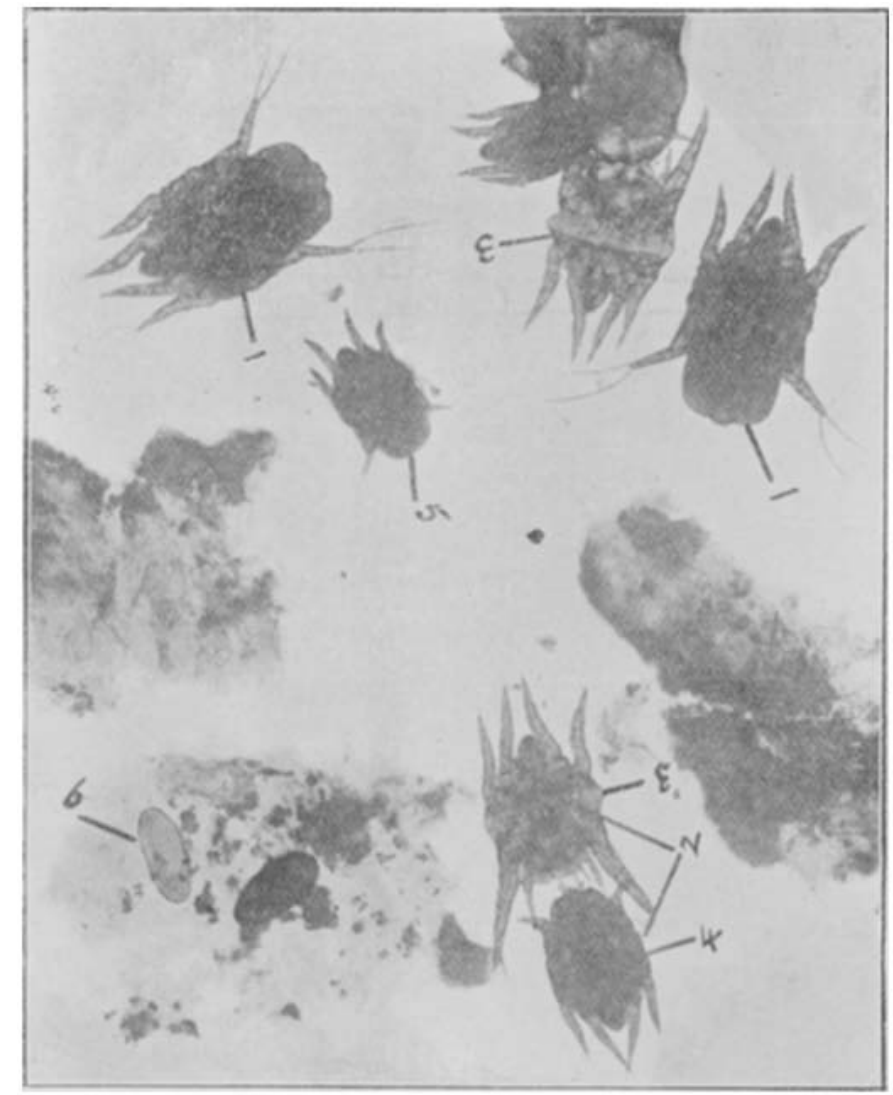

Fig. 2.

Symbiotes auricularum, slip preparation $(\times 50)$. 1. Ovigerous females. 2. Pair coupled. 3. Male. 4. Pubescent female. 5. Hexapod stage. 6. Ovum.

and see the two cats, which were continuously scratching and shaking their heads, the smell from them being very offensive in the hot close rooms. I found them both suffering from symbiotes auricularum, which were indistinguishable in all their stages of development from the acari obtained from the dog. The wild cat remained free from the disease.

The symptoms of auricular acariasis are peculiarly local, and are not noticed, as a rule, until the disease is considerably advanced, when the patient evinces irritation of the ears, manifested by holding the head on one side and constantly pawing and shaking them. An 
examination reveals the internal parts of the ear to be highly inflamed, and a quantity of dark brown cerumen more or less fills the internal concha; this cerumen is hard and dry on the surface, but underneath it is soft and moist and of a light yellowish colour, and in consistency is not unlike the peculiar sticky mucous-like exudate which is seen in sheep scab in those situations where the psoropt abounds. The smell given off from the ear is very offensive. In advanced cases the lining membrane of the ear becomes thickened and crenated to such an extent that the canal is practically closed. I have not seen any of the epileptiform symptoms which are described by Continental acarologists.

If some of the cerumen and serosity are removed from the affected ear (for this purpose I use a small thin bone ear-scoop) and examined
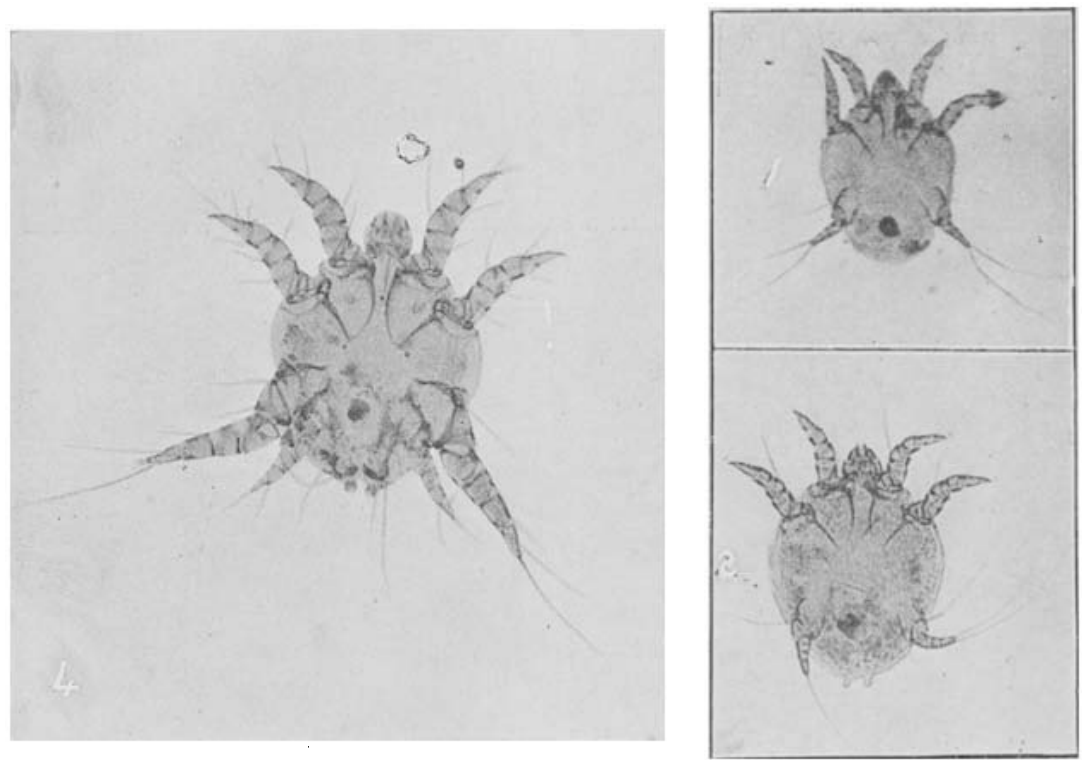

FIG. 3.

Symbiotes auricularum $(\times 70)$. 1. Hexapod larva. 2. Pubescent female. 4. Male, copulatory suckers extenderl.

uncler a hand lens, numbers of small white specks will be seen moving about, their movements being comparatively rapid; these are the symbiots, and, if the cerumen which has been removed be placed on a sheet of black paper for half an hour or so, the parasites will be found gradually to congregate together in little masses containing ten to twenty individuals or more. Sometimes even in the ear similar masses may be found and lifted off all together. If further examination is desired, the cerumen should be placed on a glass slip with a drop of clove oil upon it, and a cover glass pressed down and the preparation examined under a low power of the microscope, Zeiss a.a. or A being amply sufficient for the purposes of identification. The parasites will be seen in all stages of development from ova to adults, with many pairs in coition. The great disparity in the number of males to females which is alluded to by authorities on this subject is 
one which applies to all forms of psoric acariasis, and is not correct without considerable qualification. It depends (I) on the locality from which a given number of parasites are obtained, and (2) on the males being counted and compared with the number of ovigerous and pubescent females combined. (I) It will be found that there are more males and pubescent females together with larval and nymphal forms in the most recently invaded areas, and that the ovigerous females are more numerous towards the periphery of the scab, their
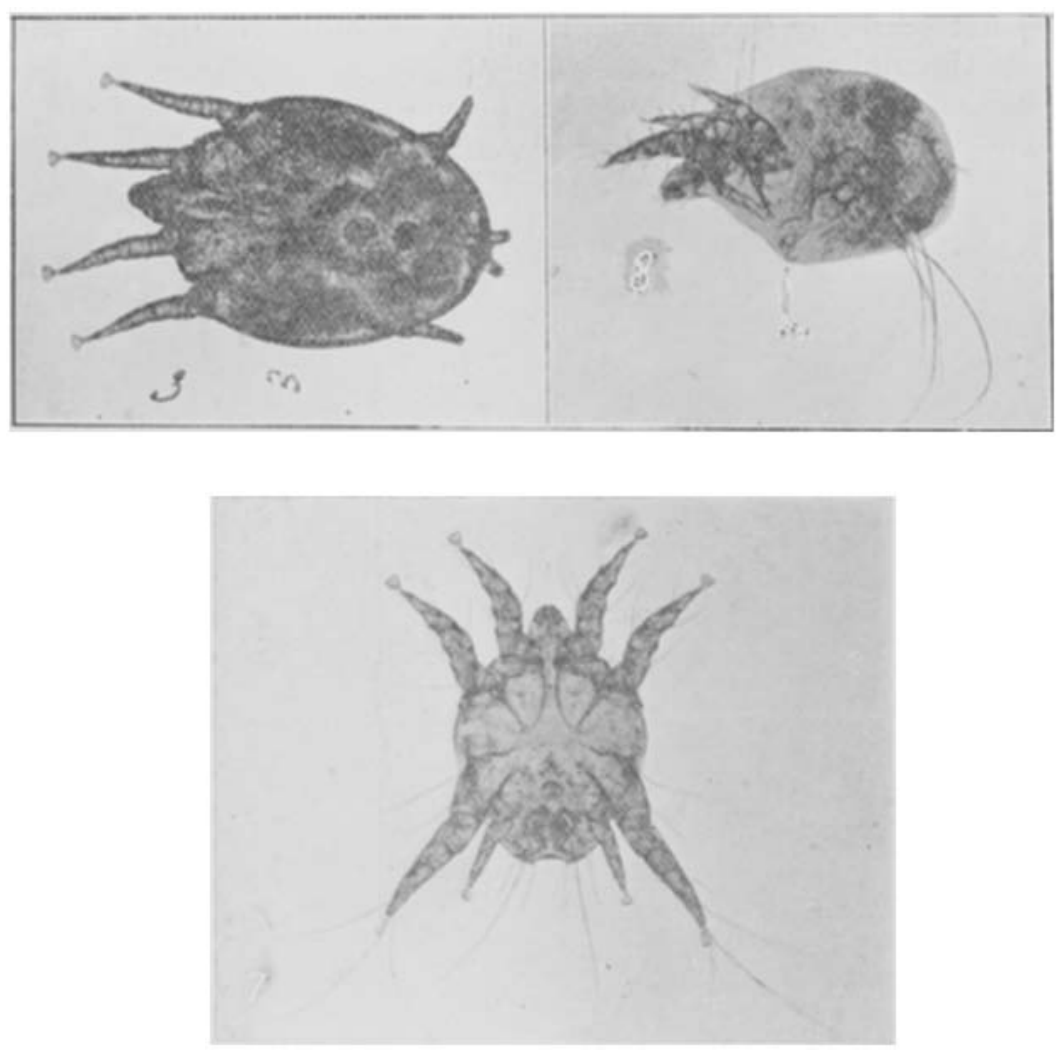

FIG. 4.

Symbiotes auricularum. 3. Pubescent female $(\times 100)$. 7. Male $(\times 70)$. 8. Ovigerous female, side view, anterior legs raised $(\times 70)$.

function in this stage being entirely devoted to depositing their ova. (2) If the number of males be compared with the number of pubescent females, the ovigerous females being disregarded, it will be found that the number of males is little, if any, less than that of the pubescent females, i.e., females in an unfecundated condition and prior to their final ecdysis.

The disease yields to any parasiticide treatment which is efficiently carried out, provided the agent used is of sufficient strength to kill the parasites and yet not strong enough to increase the irritation in the ears. 
Symbiotes auricularum are oviparous acari, differing somewhat from other species of sarcoptinæ in their life history. The development of an acarus is divided into three stages, ovum, larva, and nympha. To these must be added a fourth in the females of sarcoptinæ, which is known as the pubescent female stage. The term larva is applied to the recently-hatched acarus while it remains in a hexapod condition; the term nympha is reserved for the next stage, when it has become octopod but without external evidence of generative organs. I am

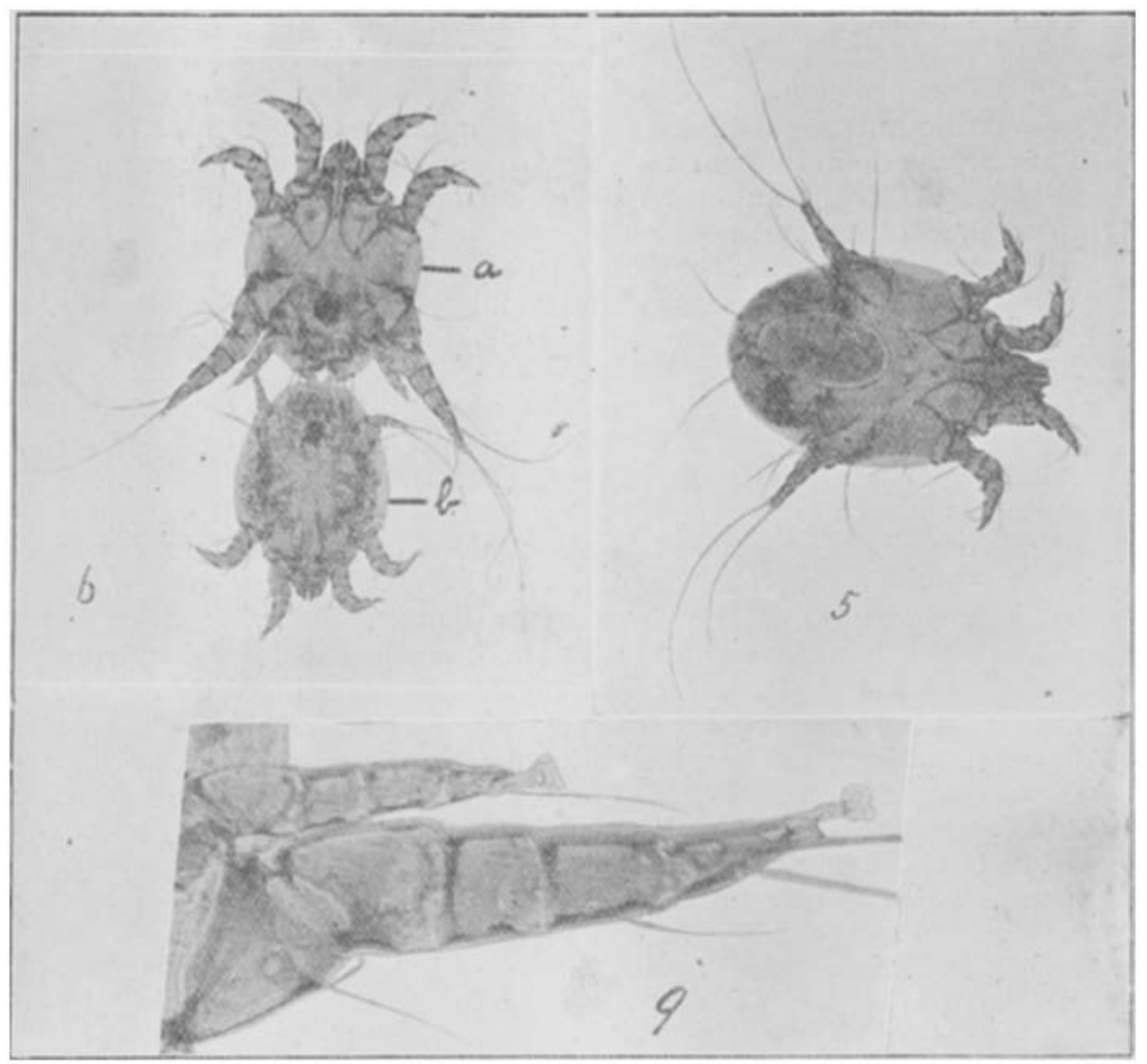

Fin. \%.

Symbiotes auricularum. 5. Ovigerous female with ovum $(\times 70)$. 6. Pair couplod-a, male; b, pubescent female $(\times 70)$. 9. Left thrid and fourth legs of male $(\times 300)$.

not aware that the development of the sarcoptinæ has been thoroughly made out, but in other sub-families of the sarcoptidx closely allied to it, as tyroglyphinæ, where observations can be more easily made, the acari pass through a single ecdysis in the larval stage and two in the nymphal, which brings them to the imago; but in addition to these in sarcoptinæ there is certainly another ecdysis in the female, which is the change from the pubescent to the ovigerous state.

The ova of symbiotes auricularum are small oval bodies, measuring $.2 \mathrm{Imm}$. long by 'I I mm. wide; they are of a white or greyish colour, 
and not more than one is seen in the oviduct at a time. They are very large compared with the size of the acarus. Through the transparent capsule of the ova, prior to hatching, the doubled-up larva may be clearly seen, the two anterior pairs of legs folded backwards and the posterior ones forwards towards the rostrum. The colour of the hexapod larva on emerging from the ovum differs but little from that of the imago; the abdomen is opaquish-white, the chitinised parts of the exoskeliton being of a pale yellow, which becomes darker in each succeeding stage of development. The two anterior pairs of legs in the larva, as in all the other stages, terminate with a small claw and a pedunculated caruncle or sucker; the third or posterior pair in two small hairs. Excepting for an increase in size, there is in symbiotes auricularum nothing to distinguish the nympha from the larva, and, following the definitions of the stage as applied to acari, the nymphal stage must be looked upon as being entirely suppressed; there is no appearance of a fourth pair of legs, and this applies also to the pubescent females, which can only be distinguished from the larva by the external generative organs, the copulatory tubercles, which are so highly developed and form such a striking feature in this species Neumann says that the fourth pair of legs of the pubescent female are reduced to knobs carrying a small hair. I have not been able to verify this in any of the large number of specimens I have examined, and have come to the conclusion that the pubescent female of symbiotes auricularum is still hexapod. The so-called vulvo-anal slit of the pubescent female is not functionally a cloaca, but only the external opening of the rectum. As long ago as I86I, Gudden discovered what is now known as the bursa copulatrix, which was rediscovered by Michael in 1879 , and confirmed by many other acarologists since. In sarcoptidæe the female is fertilised through the bursa copulatrix, a small retroanally placed opening which leads to the receptaculum seminis; this bifurcates to the ovaries and oviducts, which reunite immediately supero-posteriorly to the sub-thoracic vulva, through which the eggs are laid.

The final ecdysis of the male brings it to the pubescent or imago state, in which it differs from the other stages by the greatly developed third and fourth pair of legs. The fourth pair are larger and stronger than in any other species of sarcoptina, and the caruncle on the tarsus is equal in size to those on the other legs. The third pair of legs presents a distinctly peculiar ambulacrum (Fig. 9, 5), the tarsus being terminated by a truncated sucker in addition to the pedunculated caruncle which arises from its inner surface. The posterior lobes of the male are slightly-rounded projections carrying three hairs each, the centre one being the longest; the lobes are separated by a small notch. The copulatory suckers are situated somewhat forward from the posterior margin of the body, and are protected by roundish chitinous pieces. The average size of the male is $36 \mathrm{~mm}$. long by $.26 \mathrm{~mm}$. wide.

Coitus persists for a long time between the pubescent female and male in symbiotes auricularum, as is common with other species of sarcoptina, the coupling being brought about by the suckers of the male extending a fine membraneous sheath which envelopes the tubercles of the female, the ends of which are held by the powerful suckers of the male. It is during coition that the final ecdysis of the 
female takes place, and I believe that act is not complete till the fecundated female emerges from the exuvium.

The average size of the ovigerous female is $44 \mathrm{~mm}$. long by $3 \mathrm{~mm}$. wide. The third pair of legs in this stage are large, and terminate with two long hairs, the fourth pair of legs being rudimentary, the tarsus barely extending beyond the body and ending in two small fine hairs. The vulva is situated centrally between the posterior end of the epimera of the second and the anterior end of the epimera of the third pair of legs, the crenated appearance of the derma, with the supporting sclerates converging to the opening, being a striking feature on the ventral surface of the body.

The inadequate anatomical descriptions of symbiotes auricularum which are available, and the difference of those which are given from the ones I describe above, leave two conclusions open-either the species I describe is a new one, or the differences are due to lack of description in the previous literature. I am inclined to believe that the latter is the right explanation, though the illustrations of the male given by Neumann and his description of the pubescent female differ from mine very considerably.

In order to convey an idea of the size of symbiotes auricularum, I have given photomicrographs of that parasite and of the common psoropt which is so well known, under the same magnification.

\section{TIGKS AND MALIGNANT JAUNDICE OF THE DOG,}

\section{By Chas. P. Lounsbury, B.Sc., F.E.S., Government Entomologist, Cape Town.}

Malignant jaundice is the dog disease commonly known in South Africa as distemper, or hondziekte. The name here adopted is the one preferred and long used by the Cape Veterinary Department ; the terms malignant malaria and bilious fever have also been applied to the disease by veterinarians. As the most serious, and one of the most common diseases affecting dogs in the country, its own importance warranted the attention I have given to its means of transmission from animal to animal; but the real inducement to study its means of dissemination was the hope of acquiring knowledge that might prove of value in later investigating diseases of other animals that are of greater economic consequence. Malignant jaundice is one of a large number of diseases of man and lower animals due to the presence and multiplication of protozoan organisms in the blood; and these diseases, with others of more obscure nature, as, for instance, heartwater, horsesickness, and yellow fever, are probably all dependent on blood-sucking parasites for their transmission from animal to animal. The exact channel of infection is known in a few cases only, and, therefore, each new fact discovered in relation to the transmission of any one is a matter of considerable scientific and economic interest, since its application may be general.

Nature of the disease.-The bacteriologist of the Cape Agricultural Department, Mr Wm. Robertson, in an article which appeared in the

1 Reprinted from the Report of the Government Entomologist for 1903. 